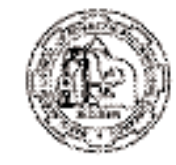

BCSIR
Avaiable online at www.babglajol.info

Bangladesh J. Sci. Ind. Res. 43(2), 235-242, 2008

\title{
Studies on the Effect of Antioxidants on the Stability of Sesame (Sesame indicum linn.) Seed Oil During Storage
}

\author{
M.S. Rahman, M.A. Hossain, G.M. Ahmed, M.M. Uddin and S. Yeasmin \\ BCSIR Laboratories, Binodpur Bazar, Rajshahi-6206, Bangladesh
}

\begin{abstract}
The oil extracted from sesame seed kernel was stored in white plastic containers using different antioxidants like Butyl hydroxy anisole-BHA, Butyl hydroxy toluene-BHT and propyl gallate-PG at various percentages (0.01-0.05\%) at room temperature for 12 months. The results were evaluated after 2months in terms of free fatty acid (FFA), iodine value and peroxide value . It was observed that the rate of increase in free fatty acid (FFA), was appreciably lower in all the three oils stored with $0.02 \%$ BHA, BHT and PG than those of the oils containing other percentages of $0.01,0.03,0.04$ and 0.05 of antioxidants.Among these three oils of sesame $(0.02 \%)$ percentages of antioxidants, the rate of increase in free fatty acid (FFA) of the oil containing $0.02 \%$ of BHA was found to be the lowest (0.1372). The iodine values of the oils were not influenced by any antioxidants of any percentages. But the rate of increase in peroxide value of the oil containing $0.02 \%$ of BHA was also found to be significantly lower. Most significant differences in storage lives was observed in the stored oil containing $0.02 \%$ of BHA.
\end{abstract}

Keynotes: Antioxidant, Free fatty acid, Iodine value, Peroxide value. Storage life, Fat-oxidant.

\section{Introduction}

Sesame (Sesame indicum linn.) is one of the most important oil seed crops in Bangladesh. It occupies the second position among the oil seeds in respect of both acreage and production after mustard seed. Sesame is cultivated widely more or less in all the districts of Bangladesh. The climate and soil-texture of Bangladesh are quite suitable for its cultivation. Its seed contains $42-45 \%$ pale-yellow coloured edible oil. The oil possesses a high degree of resistance to oxidative rancidity (Anon 1972). The bulk of the oil is utilized for edible purposes (Mowlah et al 1990). The oil is consumed largely as cooking, salad and also employed in sweetmeat making and in adulteration of ghee (Mattil et al 1964, Watt 1972). The oil is a high quality oil and is used in cooking fats, margarine and

\footnotetext{
* Corresponding author
} 
salad oils (Egan et al 1981). The oil is also used largely as an edible oil, table oils in salad dressing (Anon 1950).

The oil is used as shortening, salad and margarine (Gesses et al 1972). The oil is also used in the manufacture of soap, cosmetics, perfumes and pharmaceuticals products (Ninan 1989). At present Bangladesh is facing acute shortage of edible oils and she is compelled to import edible oils from abroad (Ali et al 1997). So sesame oil can play a vital role in bridging the vegetable oil gap in the country.

Though the oil is one of the chief sources of vegetable oil, yet the oil is not so popular in our country. There may be two reasons behind it, firstly, most of the people of our country are quite ignorant about the quality of the oil and secondly, the oils are not properly stored due to the lack of appropriate knowledge for which the oils lose their commercial gradation to a great extent.

The storage lives of the oil can be increased by using certain antioxidants. For the selection of the antioxidants the following important points must be taken into account. The antioxidants must have adequate potency, contribute no off-flavouror odours to the products in which they are used and the economically attractive when compared to other methods for inhibiting fat oxidant such as vacuum packaging, low-temperature, storage and others. The antioxidant formulation most commonly used in edible products contain various percentages of BHA, BHT and propyl gallate. There are some other antioxidants like octyl gallate dodecyl gallate, tecopherols, which lack potency in most products compared to BHA, BHT and propyl gallate. There are also several sulphur-contaning compounds such as thiodipropionate but their relative in effectiveness producing some off odour and flavour problems have been discouraged their use in food products.

Considering all the factors described above, we have used certain percentages of BHA, BHT and propyl gallate in our storage studies. Generally the quality of an oil is mainly characterized by the level of free fatty acids (FFA), peroxide value and iodine value. So in our studies we keenly observed the changes of these factors by using the antioxidant as oil stabilizers for preserving better oil quality.

\section{Materials and Methods}

Fresh and matured sesame seeds were collected from the local market. The seeds were then dishelled manually and the kernels thus obtained were crushed into smaller particles in a glass mortar and dried in the sun for 2 consecutive days and then in the oven at a temperature of $105^{\circ} \mathrm{C}$ for about $1 / 2$ an hour to about $4-6 \%$ moisture. The moisture content in the fresh kernels was determined by IUPAC method (Anon 1979). The oil was then extracted with n-hexane in a Soxhlet apparatus for 8 hours because cold pressed oil shows less storage stability than corre- 
sponding solvent extracted oil (Pominski et al 1970). The oil was recovered by the evaporation of the solvent under reduced pressure using a rotary vacuum evaporator. The oil thus obtained was then packed in twenty-six oz white plastic containers with different percentages (0.01-0.05) of antioxidants and then kept on a laboratory bench at room temperature exposed to light.

The percentage of free fatty acid (FFA) and peroxide value of the oils were determined by the standard AOCS method (Anon 1955). Hanus method was followed to determine the iodine value of the oils (Anon 1980). Storage lives of the oils were determined on the basis of organoleptic tests (Prasad et al 1959).

\section{Results and Discussion}

The changes in free fatty acid (FFA) of the sesame seed oil stored by using different percentages of antioxidants was represented in Table I. From Table I, it was found that the rate of increase in free fatty acid (FFA) of the oil stored with $0.02 \%$ of BHA remained low throughout the whole period of storage. Slight increase in free fatty acid (FFA) was noticed in the oils stored with other percentages of BHA 0.01, 0.03,0.04 and 0.01, 0.02, 0.03 percentages of BHT. But the rate of increase in FFA was higher in all the samples containing propyl gallate of all percentages.
The changes of iodine values of the oils stored by using different percentages of antioxidants were shown in Table II. From the table it was observed that the iodine values were not influenced by any antioxidants.

The changes in peroxide values of the oils were depicted in Table III. It was noticed that the rate of increase in peroxide values were significantly lower when it was stored with $0.02 \%$ BHA. but the values were found to be higher in all other sample of BHA excepting the oil containing $0.02 \%$ of the same antioxidant. Higher peroxide values (7.4-8.9) were also found in all the samples containing PG of all percentages. But these values are slightly lower than those of the oils containing BHT of all percentages. The highest peroxide value (8.9) was attended by the oil stored with $0.05 \%$ of PG.

The storage lives of the oils was recorded in Table IV. It was observed that the differences in the storage lives of the oil stored with $0.02 \%$ of BHA were most significant. The oil stored with $0.01,0.03,0.04,0.05 \%$ of BHA and 0.01, 0.02, 0.03 of BHT did not differ significantly from one another in respect of their storage lives. But the storage lives of the oils were not influenced by PG of any percentages. 


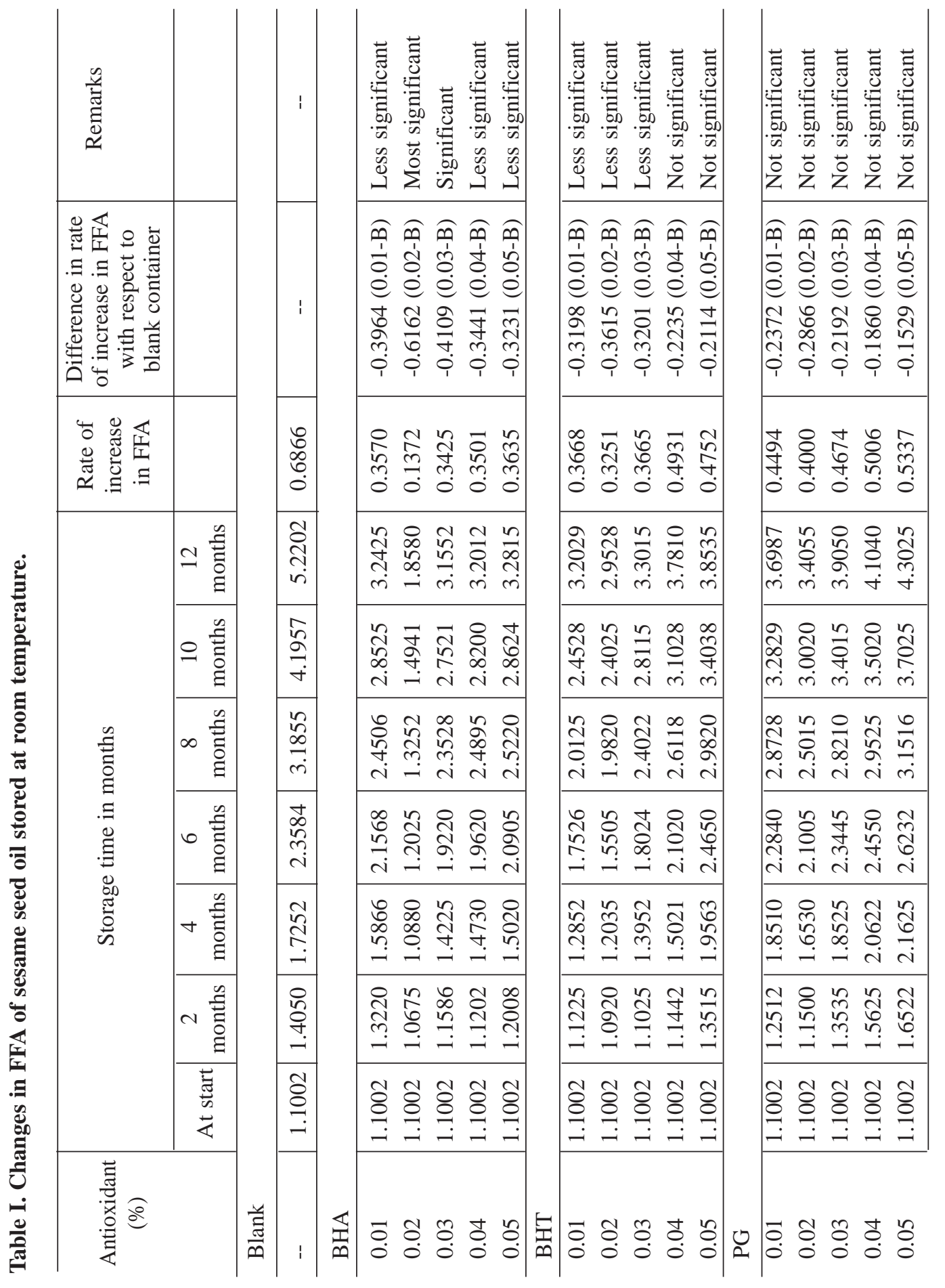




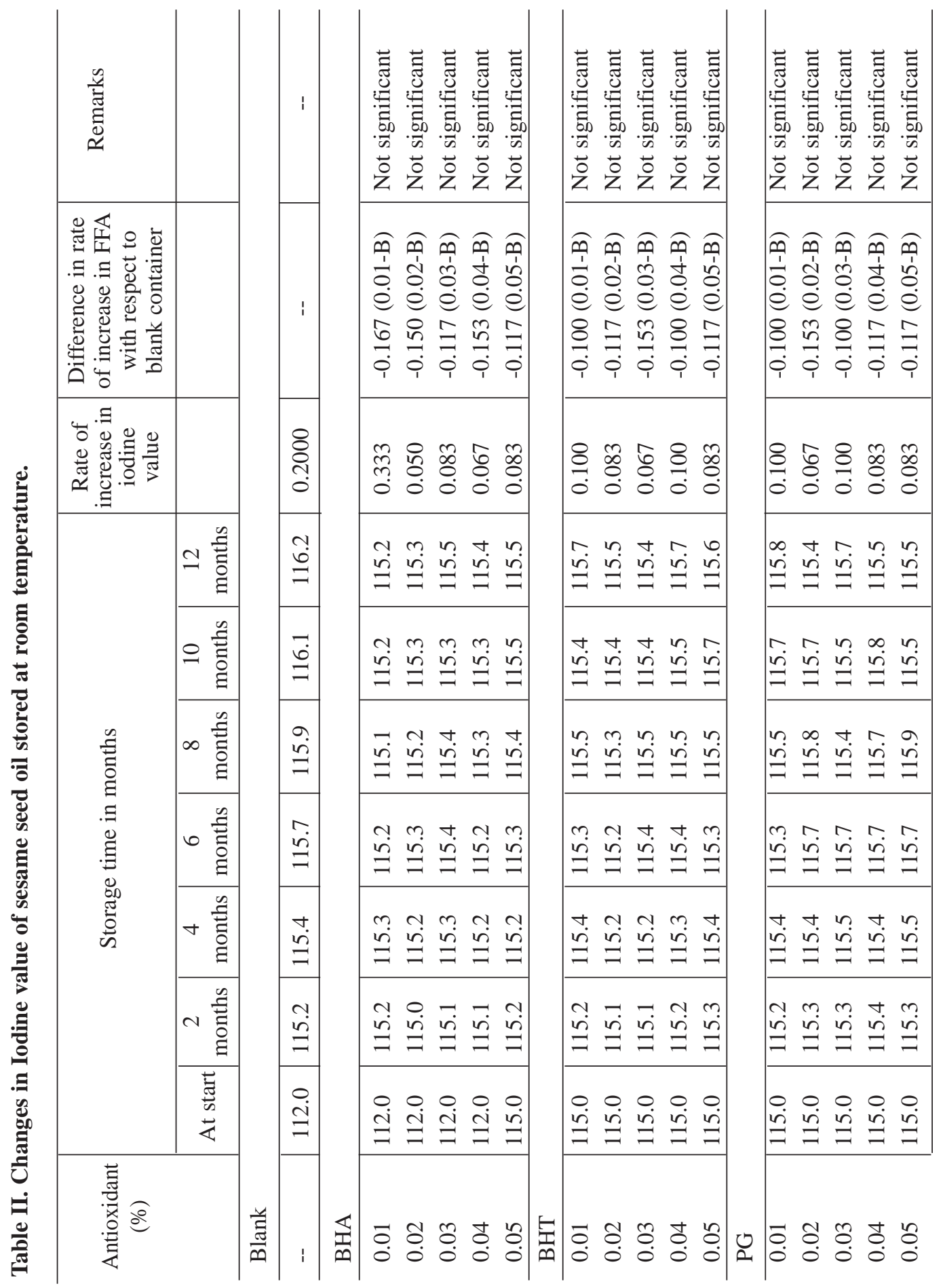




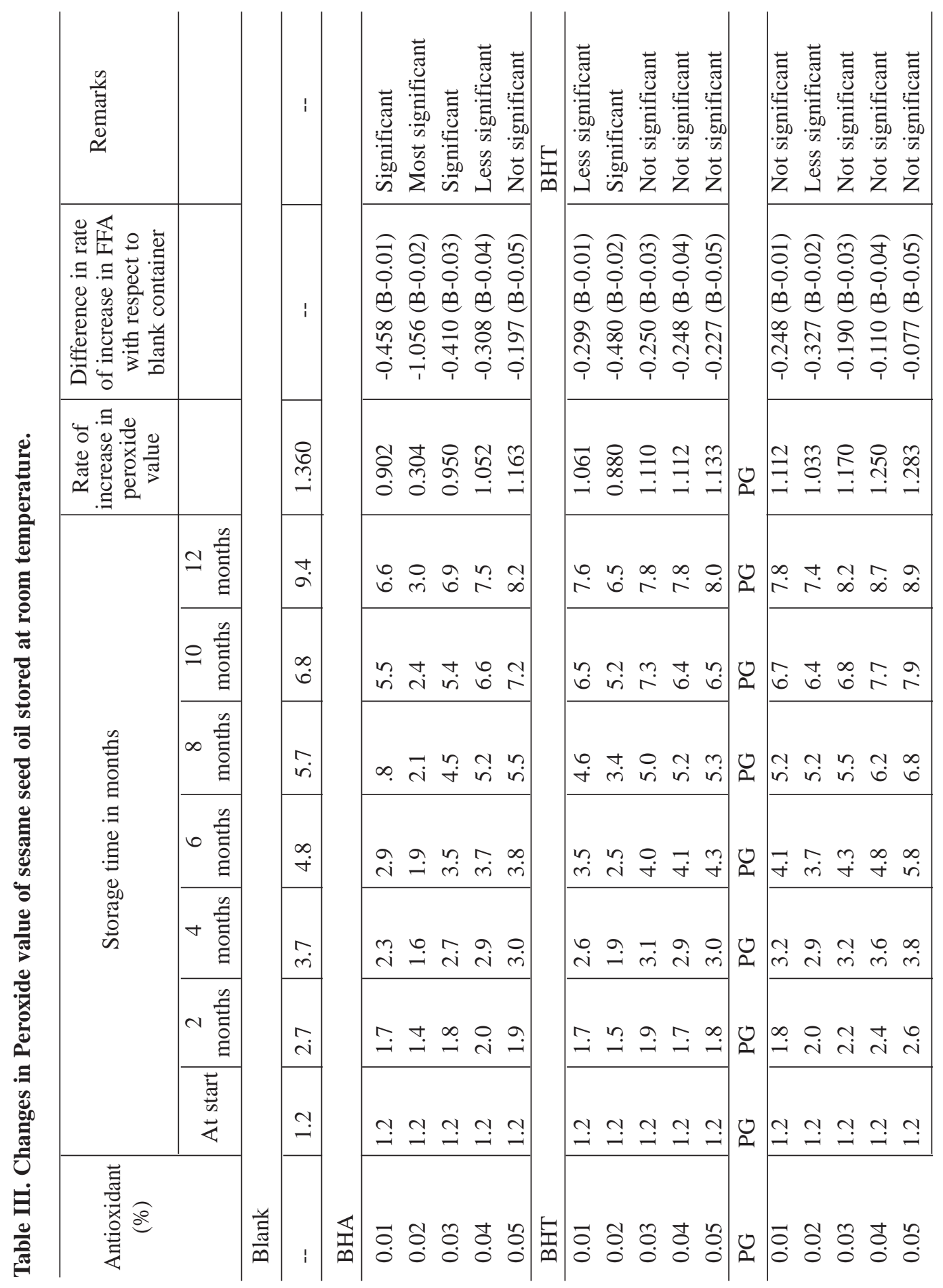


Table IV. Storage lives of sesame seed oil (storage lives determined on the basis of organoleptic test)

\begin{tabular}{|c|c|c|c|}
\hline Antioxidant (\%) & $\begin{array}{l}\text { Mean storage life } \\
\text { in month }\end{array}$ & $\begin{array}{c}\text { Difference in storage } \\
\text { life with respect to blank } \\
\text { container }\end{array}$ & Remarks \\
\hline \multicolumn{4}{|l|}{ Blank } \\
\hline & 7.5 & -- & -- \\
\hline \multicolumn{4}{|l|}{ BHA } \\
\hline 0.01 & 8.5 & $1.0(0.01-B)$ & Less significant \\
\hline 0.02 & 11.0 & $3.5(0.02-B)$ & Most significant \\
\hline 0.03 & 9.0 & $1.5(0.03-B)$ & Significant \\
\hline 0.04 & 9.0 & $1.6(0.04-B)$ & Significant \\
\hline 0.05 & 8.5 & $1.0(0.05-B$ & Less significant \\
\hline \multicolumn{4}{|l|}{$\mathrm{BHT}$} \\
\hline 0.01 & 8.5 & $1.0(0.01-B)$ & Less significant \\
\hline 0.02 & 9.2 & $1.7(0.02-B)$ & Significant \\
\hline 0.03 & 9.0 & $1.5(0.03-B)$ & Significant \\
\hline 0.04 & 8.4 & $0.9(0.04-B)$ & Not significant \\
\hline 0.05 & 8.3 & $0.8(0.05-\mathrm{B}$ & \\
\hline \multicolumn{4}{|l|}{ PG } \\
\hline 0.01 & 8.4 & $0.9(0.01-B)$ & Not significant \\
\hline 0.02 & 8.3 & $0.8(0.02-\mathrm{B})$ & Not significant \\
\hline 0.03 & 7.9 & $0.4(0.03-B)$ & Not significant \\
\hline 0.04 & 7.9 & $0.4(0.04-B)$ & Not significant \\
\hline 0.05 & 8.0 & $0.5(0.05-B$ & Not significant \\
\hline
\end{tabular}

\section{Conclusion}

Sesame seed is one of the chief sources of vegetable oil. As Bangladesh is facing acute shortage of edible oils, so it can bridge the vegetable oil gap in the country if proper step can be taken regarding its storage lives. Increasing of storage lives of an oil is necessary for its long time preservation. To find out the required percentages of a certain antioxidant for the preservation of any oil is very essential. For increasing storage lives of sesame seed oil certain antioxidant may be used. In our experiment we observed that the development of rancidity was least when the oil was stored with $0.02 \%$ of BHA. So, it is suggested that sesame oils should be stored with $0.02 \%$ of BHA for preservation to keep better quality of oil. 


\section{Acknowledgement}

Th authors express their gratitude to Dr. Shirina Begum, Director-in-Charge, BCSIR Laboratories, Rajshahi for providing necessary laboratory facilities.

\section{References}

Anon (1950). Thorpe's Dictionary of Applied Chemistry. 4th ed., 720.

Anon. (1955) Association of Official Agricultural Chemists; Official Methods of Analysis, Washington, 8th ed., 468.

Anon. (1979). International Union of Pure and Applied Chemistry, Standard Methods for the Analysis of Oils, Fats and Derivatives, Pergamon Press, 6th ed, 126.

Anon. (1980). Official and Tentative Methods of the American Oil Chemists Society (1-2), 3rd ed., 4-38.

Anon. (1972). The Wealth of India, A Dictionary of Indian Raw Materials and Industrial Products, IX: 288.

Ali, M.H., Rahman, M.S., Ahmed, G.M., Hossain, M.A. Uddin, M.A. (1997) Studies on the effect of different solvent mixture for the extraction of ground nut seed lipids. Bangladesh J. Sc. Ind. Res, 32 (2) :166.
Egan, H. Kirk, R.S. Sawyer, R. (1981) Pearson's Chemical Analysis of Fats, 8th ed., 518.

Gessner and Howely, G. (1972) The Condensed Chemical Dictionary. 9th ed., 770.

Mattil, K.F. Norris, F.A, Stirton, A.J. \& Swern, D. (1964) Baileys Industrial Oil and Fat Products. 3rd ed. 208.

Mowlah, G. Seik, N.M and Kamal, A.S.M, (1990) A hand book on edible oils and fats, 1st ed, 157.

Ninan, K. N. (1989) Edible Oil Seed, 1st ed., 43.

Pominski, J. Pearce, H. M. Spadaro, J.J. (1970) Food Technology, 24: 92-94.

Prasad, M. Mathur, P. B. 1959. Studies in Packaging Transportation and Storage of some Vegetable Oils. J. Sci. Ind. Res. Vol. 18A; 571-575.

Watt, G. (1972) A Dictionary of the Economic products of India, VI(II): 2nd ed., 510.

Received : August 13, 2007;

Accepted : December 17, 2007 